\title{
Comparative performance analysis of Thyristor and IGBT based induction motor soft starters
}

\author{
Ahmed Riyaz ${ }^{1}$, Atif Iqbal ${ }^{1}$, Shaikh Moinoddin ${ }^{1}$, SK. MoinAhmed ${ }^{1}$, \\ Haitham Abu-Rub ${ }^{2}$ \\ ${ }^{1}$ * Department of Electrical Engineering, Aligarh Muslim University, Aligarh (UP), India \\ ${ }^{2}$ Electrical \& Computer Engineering programme, Texas A\&M University at Qatar, Doha, Qatar \\ "Corresponding author (e-mail: atif_iqbal1@ rediffmail.com)
}

\begin{abstract}
In this paper the performance of a split-phase motor and a three-phase induction motor drives for soft starting is evaluated. The paper systematically investigates and compares the characteristics of a variable voltage fed induction motor drive for two different types of soft starters; one based on IGBT and another based on Thyristor. Experimental validation is done using analogue circuit based system, developed in the laboratory. The novelty of the work lies in the development of simple and flexible models for simulation purpose and their experimental validation.
\end{abstract}

Keywords: Variable speed electric drives, Soft starter, Thyristor, IGBT

\section{Introduction}

Direct on-line starting of large induction motors poses a great problem to the grid as well as the motor itself due to sudden voltage dips and large fluctuating torque, Willams and Griffth (1978), Bruce et al. (1984) and Nevelsteen and Aragon (1989). Some time due to tripping of under-voltage and over-load relays the motor may fail to start. Alternatively reduced voltage starting is being used especially for starting of large induction machines using auto-transformers. However, the volume and the cost of auto-transformers limit its use. Power Electronics converter based induction motor starters more commonly called soft starter are becoming popular and are rapidly replacing the conventional reduced voltage starters using auto-transformers, Shephard (1976), Mazda (1973), Mozder and Bose (1976), Rashid (1993), Rowan and Merrison (1991), Lipo (1971a) and Lipo (1971b). Two topologies of soft starters are more commonly employed

- Back-to-back connected thyristor based soft starters also called ac voltage regulators.

- Insulated Gate bipolar transistor (IGBT) and gate turn-off thyristor (GTO) based dc link converter.

Thyristor based soft starters are economical, simple, and reliable. They can be economically employed in medium voltage large induction motor starting where the starting torque requirement is low. By using power electronics converter based starting, the initial inrush current of motor can be reduced significantly. Additionally they offer smooth acceleration, ease in implementation of current control, and energy savings with a partial load can be available. The thyristors are initially triggered at a large firing angle (reduced voltage) when soft started, followed by decrease in the firing angle and subsequently increase in the applied voltage to the motor. The initial starting torque at standstill of an induction motor is proportional to the square of the applied voltage. Thus this surely affects the starting of induction motor on load. Additionally the output voltage quality is poor with high distortion and poor power factor. The problem of higher THD is more prominent at large firing angle. This method is highly efficient if the motor is working under light load condition as demonstrated in Eltamaly et al. (2007a), Eltamaly et al. (2007b), Vazquez et al. (2008) and Hamed and Chalmers (1990).

Numerous attempts have been made worldwide to improve the performance of the soft starters and a number of different variants are evolved, Jang and Choe (1998), Deleroi et al. (1989), Zenginobuz et al. (2004), Gastli and Ahmed (2005), and Kashif and Saqib (2007). A step-up/down ac voltage regulator is used by Hyun and Choe (1998), in which the transformer with tap 
changer and PWM chopper, is reported. The proposed regulator topology can step up or down the output voltage by the tap changer of transformer and offers accurate output voltage to load by adjusting the PWM chopper. The major improvement with this scheme is the continuous ac side input current in contrast to the conventional ac regulator where the input current happens to be discontinuous. In Deleroi et al. (1989) a switching function is defined based on triggering angle of the thyristor and is implemented in the controller. The transient response is improved considerably with such technique. The performance of induction motor starter using soft starter is improved considerably by Zenginobuz (2004) where the starting is optimized in such as way to eliminate the supply frequency torque pulsation. Artificial intelligence based techniques have been employed to improve the starting characteristics by Gastli and Ahmed (2005) and Kashif and Saqib (2007). More recently Zhong et al. (2009) have adopted the pump control soft start scheme to improve the starting behaviour of induction machine. PWM signals are generated by the control unit which triggers the thyristors to keep the current within the specified limit. The pump control is a torque control method which uses PID control to adjust the motor torque. On the other hand Bernatt et al. (2009), have proposed special design of rotor cage of large induction machine for better starting performance. Eltamaly et al. (2009) have proposed digital firing scheme of triacs based on the current shape of the input. The sensor detects the operating mode and accordingly the triacs gate pulses are generated. Charles and Bhuvameswari (2009) have utilised shunt active filter between the ac voltage controller and input grid supply to mitigate the power quality problem arises due to the ac voltage controller acting alone.

This paper focuses on the classical topology of the soft starter based on thyristor and IGBT power switches for both single-phase and three-phase induction motors. A complete simulation model is obtained using Matlab/Simulink software for the proposed topologies. Then a prototype analog circuit based soft starter is developed in the laboratory and the simulation results are verified using experimental implementation of the same. Thus the major objectives of the paper include the development of simple and flexible simulation model for the soft starters of induction machine. The behaviour of the starters can be easily verified by the proposed simulation models. The paper is organised in five sections; the second section deals with the single-phase system, the second section details the implementation of three-phase drive system, the third section details the experimental investigation followed by the conclusion and references.

\section{Matlab ${ }^{\circledR} /$ Simulink ${ }^{\circledR}$ model development}

In the modern era, almost all the processes and techniques are at first simulated before their actual real time implementation. This reduces a significant portion of effort and cost of real time implementation. The performance of the proposed system/process/technique can be evaluated accurately by using proper simulation models. Thus the models should be flexible and accurate to take into account the real time implementation issues as well. With the rapid development in computer hardware and software, new simulation packages which are much faster and more user friendly are now available. This paper discusses the use of one such software, the SIMULINK software of MATLAB. The main advantage of the SIMULINK over other programming software is that, instead of compilation the simulation model is built systematically by means of function blocks. A set of machine differential equations can be modelled by interconnection of appropriate blocks, each of which performs a specific mathematical operation. Programming efforts are drastically reduced and the debugging of errors is easy. Since the SIMULINK is model operation programme, the simulation model can be easily developed by addition of new sub-models to cater for various control functions. The induction motor could be incorporated in the complete electric motor drive system from Simulink Library. Simulink modelling of single-phase and three-phase voltage regulators of two types i.e., thyristor and IGBT based are done and the results are evaluated in the subsequent sections.

\subsection{Matlab ${ }^{\circledR} /$ Simulink ${ }^{\circledR}$ model of single-phase soft starter using Thyristor}

The complete simulation model of a single-phase voltage regulator for soft starting of induction machine using thyristors is shown in Figure 1. Single-phase sinusoidal voltage is generated using voltage source block from Simulink Library. Gate pulses generated by subsystem (shown in Figure 2) are given to the anti-parallel thyristors. The switching signals have either 0 (turn off) or 1 (turn on). The load is taken as a simple R-L load and a split phase capacitor start motor. The model shown in Fig. 1 depicts R$\mathrm{L}$ load while motor simply replaces this load and the results are elaborated for both R-L and motor load. Simulation is carried out to determine the total harmonic distortion in the output current and the resulting values are listed in Table I for both R-L load and single-phase motor load. 


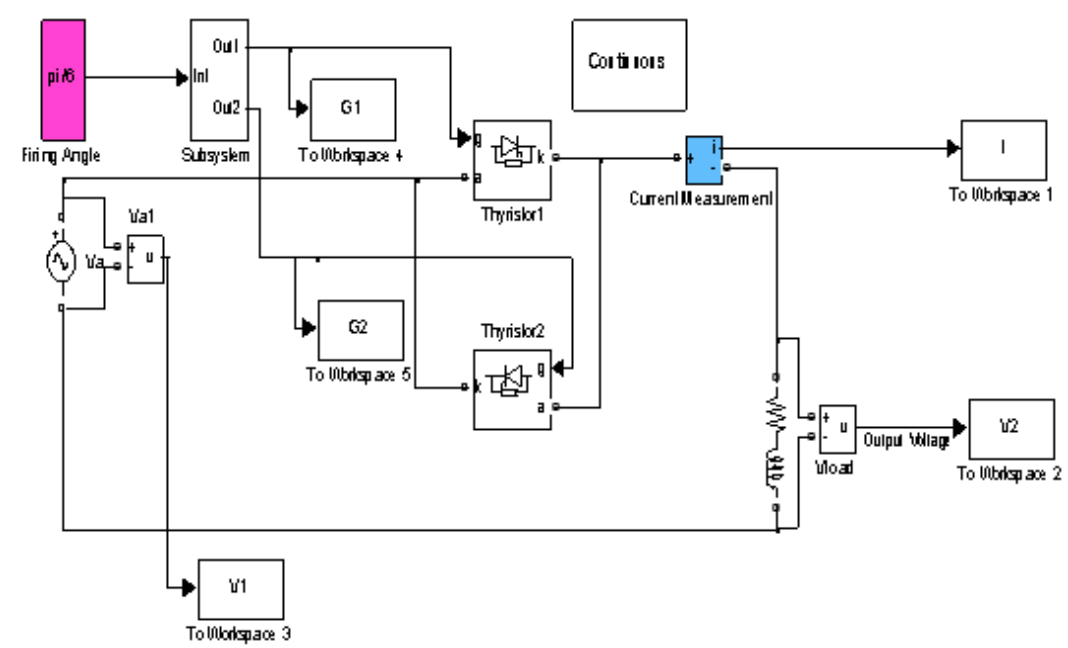

Figure 1. Single-Phase soft starter using Thyristors with R-L load.

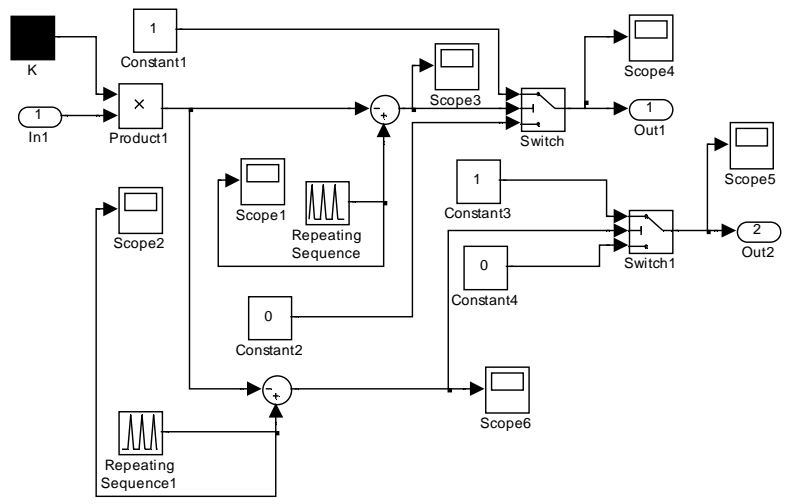

Figure 2. Subsystem for generation of gate pulses.

Table 1. THD for various firing angle for thyristor based soft starter.

\begin{tabular}{|c|c|c|}
\hline Firing Angle $(\alpha)$ & \multicolumn{2}{|c|}{$\begin{array}{c}\text { Total Harmonic Distortion(THD) } \\
\text { (\% of Fundamental) }\end{array}$} \\
\hline & R-L Load & Split-phase Induction Motor \\
\hline$\pi / 18$ & 1.71 & 0.19 \\
\hline$\pi / 12$ & 2.55 & 0.20 \\
\hline$\pi / 6$ & 9.18 & 0.24 \\
\hline$\pi / 4$ & 18.87 & 7.37 \\
\hline$\pi / 3$ & 30.18 & 16.39 \\
\hline
\end{tabular}

The controllable range of firing angle $(\alpha)$ is from $\alpha=0$ to $\alpha=\pi / 2$. However, the table shows the THD for conduction angle of upto 60 degrees. The Total Harmonic Distortion (THD) increases for higher values of $\alpha$, which indicates the increased harmonics in the line current and voltages (Table I). It is to be noted that the THD is significantly lower for motor load compared to the corresponding R-L load. The motor speed response to various conduction angles are illustrated in Figure 3. It is clearly observed that the response is faster for smaller conduction angle and the response becomes slower for progressively increasing conduction angle. This is due to obvious reason of lower average output voltages.

The torque response and stator and rotor current waveforms of split-phase motor for conduction angle of $60^{\circ}$ are illustrated in Figure 4-5. A typical motor response is observed, the stator current and torque settles to it their steady-state values once the motor attains the steady state speed. On the other hand it is observed that the speed response contains ripple.

The voltage and current waveforms for single-phase soft starter for R-L load is shown in Figure 6. The firing angle of the thyristor is assumed as $\alpha$ and the extinction angle is considered as $\beta$. It is seen from Figure 6 that $\beta=\pi-\alpha$. 


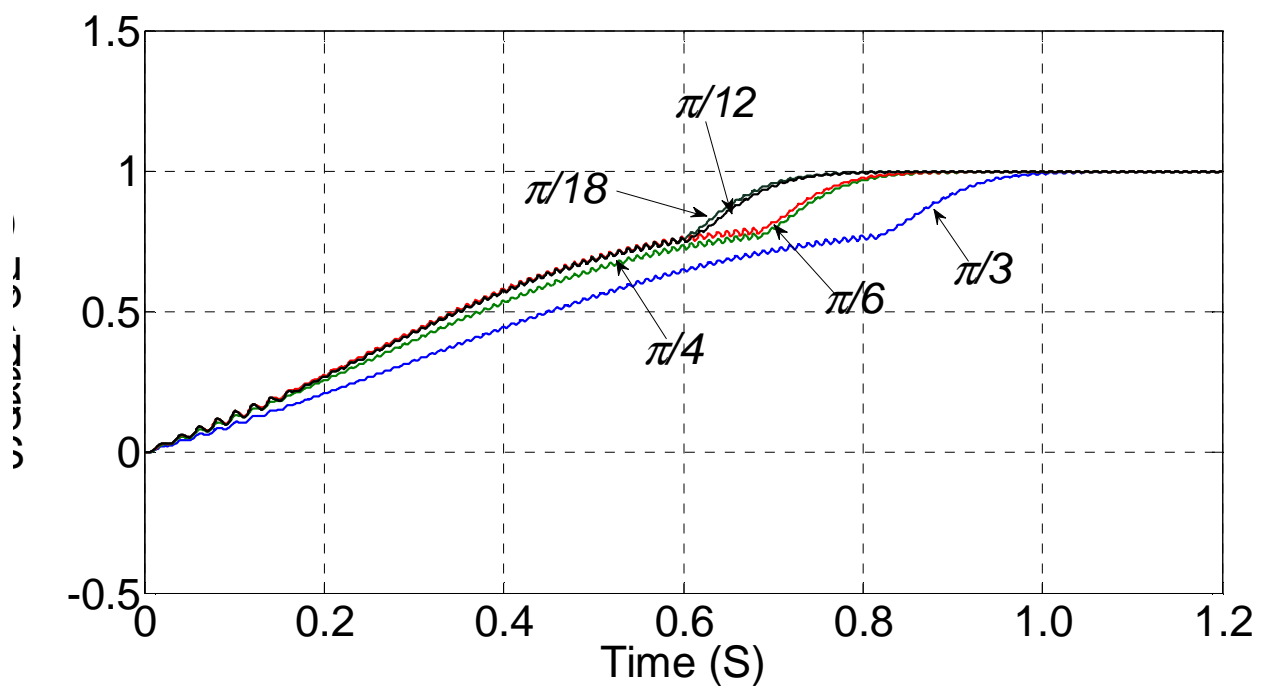

Figure 3. Speed vs time for varying conduction angles for thyristor based soft starter.

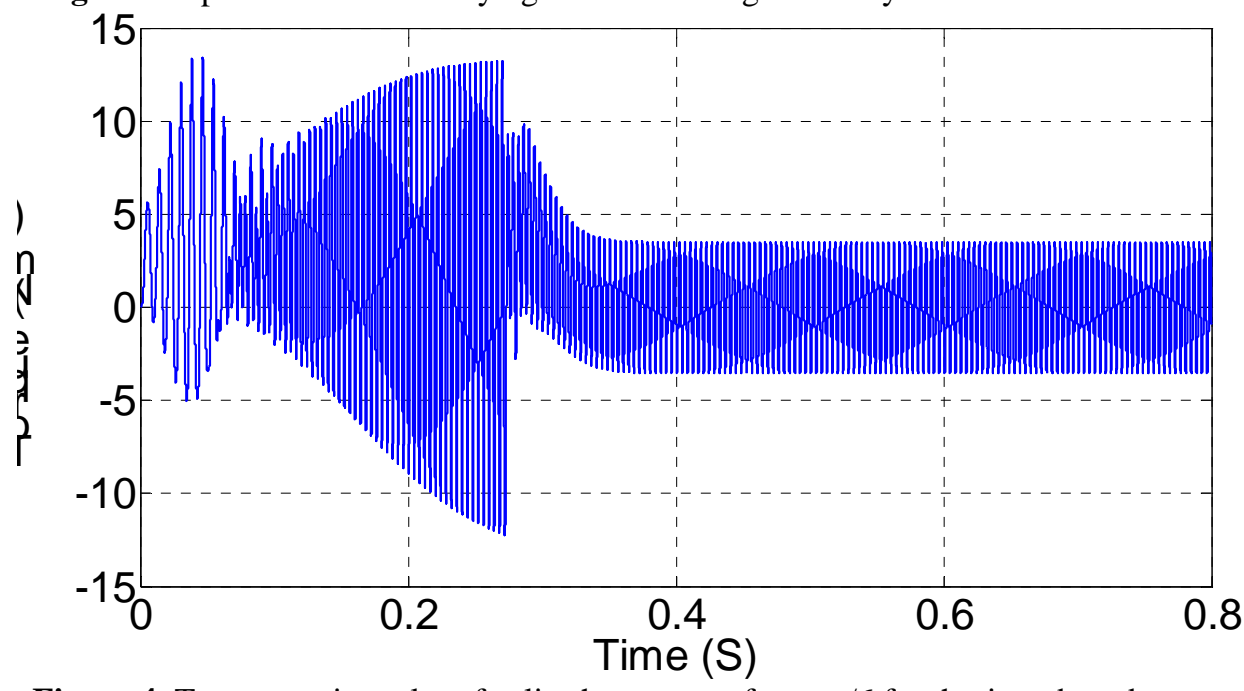

Figure 4. Torque vs time plot of split-phase motor for $\alpha=\pi / 6$ for thyristor based starter

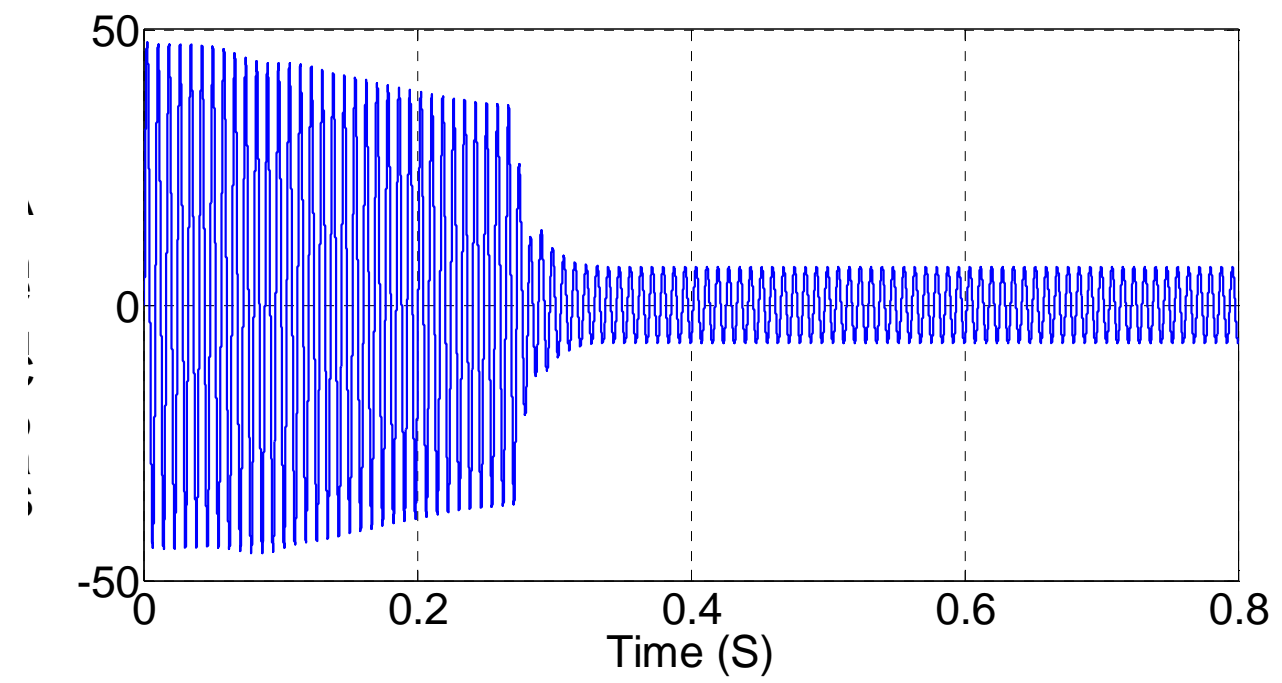

Figure 5. Stator current waveform of split-phase motor for $\alpha=\pi / 6$ for thyristor based starter.

Figure 6 shows the typical voltage and current waveforms for the single-phase soft starter of Fig. 1 with R-L load. Since, the value of $\mathrm{L}$ is very low compared to the value of $\mathrm{R}$; it behaves as mainly resistive load. Thus, the output voltage and current waveforms have half-wave symmetry without dc component. 


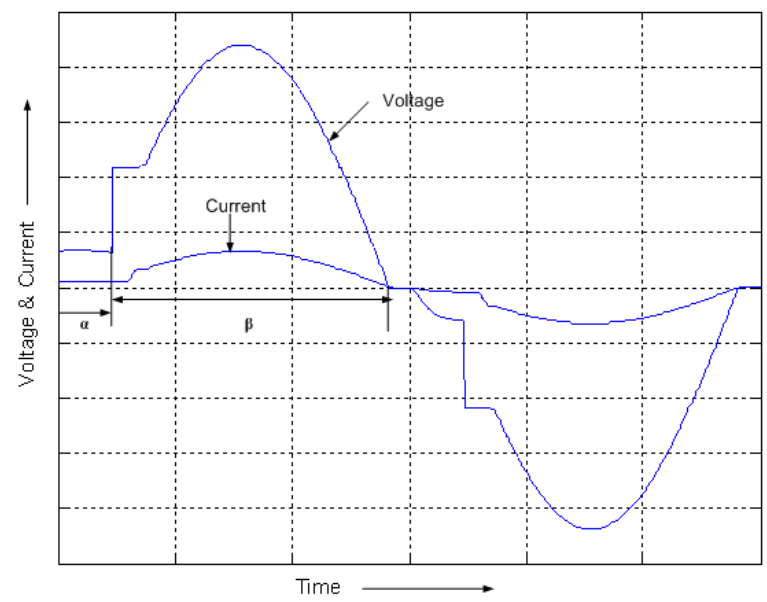

Figure 6. Output Voltage and Current for firing angle $\alpha$.

The gate pulse given to Thyristor 1 turns it 'on' at $\alpha$ and its conduction continues till $\pi$ (which is assumed as extinction angle, $\beta$ ) . Similarly, the gate pulse given to Thyristor 2 turns it 'on' at $(\pi+\alpha)$ and its conduction continues till $2 \pi$. Here natural or line commutation of Thyristor 1 and Thyristor 2 takes place at $\pi$ and $2 \pi$, respectively. If it is assumed that $v_{s}=\sqrt{2} V_{s} \sin \omega t$ is the source voltage, then the rms output voltage with Thyristor 1 triggered at $\alpha$ can be found from the half-wave symmetry as

$$
V_{o}=\left[\frac{1}{\pi} \int_{\alpha}^{\pi} 2 V_{s}^{2} \sin ^{2}(\omega t) d(\omega t)\right]^{1 / 2}=V_{s}\left[1-\frac{\alpha}{\pi}+\frac{\sin (2 \alpha)}{2 \pi}\right]^{1 / 2}
$$

Note that $V_{o}$ can be varied from $V_{s}$ to 0 by varying $\alpha$ from 0 to $\pi$. The rms value of load current

$$
I_{o}=\frac{V_{o}}{R}
$$

The input power factor

$$
\frac{P_{o}}{V A}=\frac{V_{o}}{V_{s}}=\left[1-\frac{\alpha}{\pi}+\frac{\sin (2 \alpha)}{2 \pi}\right]^{1 / 2}
$$

The average thyristor current

$$
I_{A, T h y}=\frac{1}{2 \pi R} \int_{\alpha}^{\pi} \sqrt{2} V_{s} \sin (\omega t) d(\omega t)
$$

As each thyristor carries half the line current, the rms current in each thyristor is

$$
I_{o, T h y}=\frac{I_{o}}{\sqrt{2}}
$$

\subsection{Matlab ${ }^{\circledR} /$ Simulink $^{\circledR}$ Model of IGBT Based Single-phase Soft Starter}

There is an increasing trend of using fast switching devices for several industrial applications. Thyristors are known to have low switching frequency of the order of hundreds of Hz. Hence the alternative is to use fast switching devices such as MOSFETs and IGBTs. Thus a simulation model is developed in this section incorporating a soft start system using IGBTs as shown in Figure 7. The motor speed response to various conduction angles are depicted in Figure 8. It is once again observed that the response settling time is inversely proportional to the conduction angle. Moreover, the speed response is smoother compared to the thyristor soft starts case (Figure 3). However, the settling time of speed response is lower in the previous case. The THDs are evaluated for different firing angles for both R-L load and single-phase motor load and are listed in Table 2. 


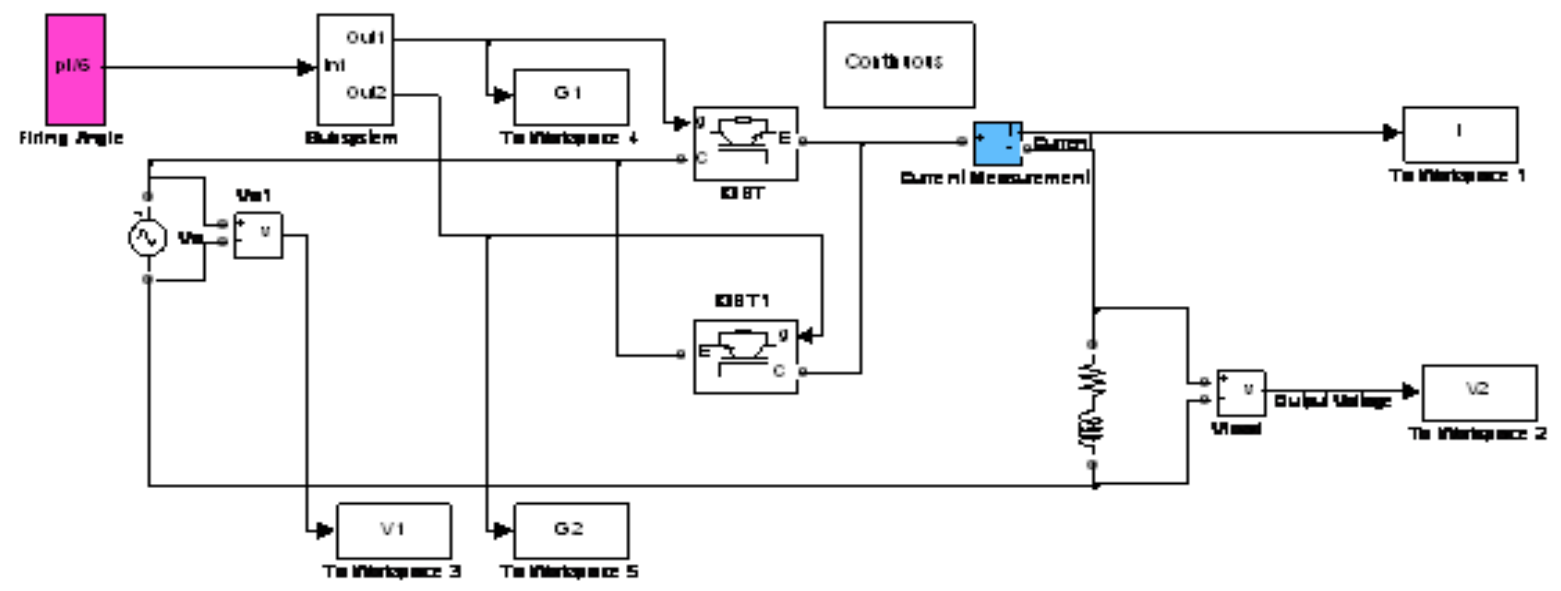

Figure 7. Simulink model of a Single-Phase soft starter using IGBT with R-L load.

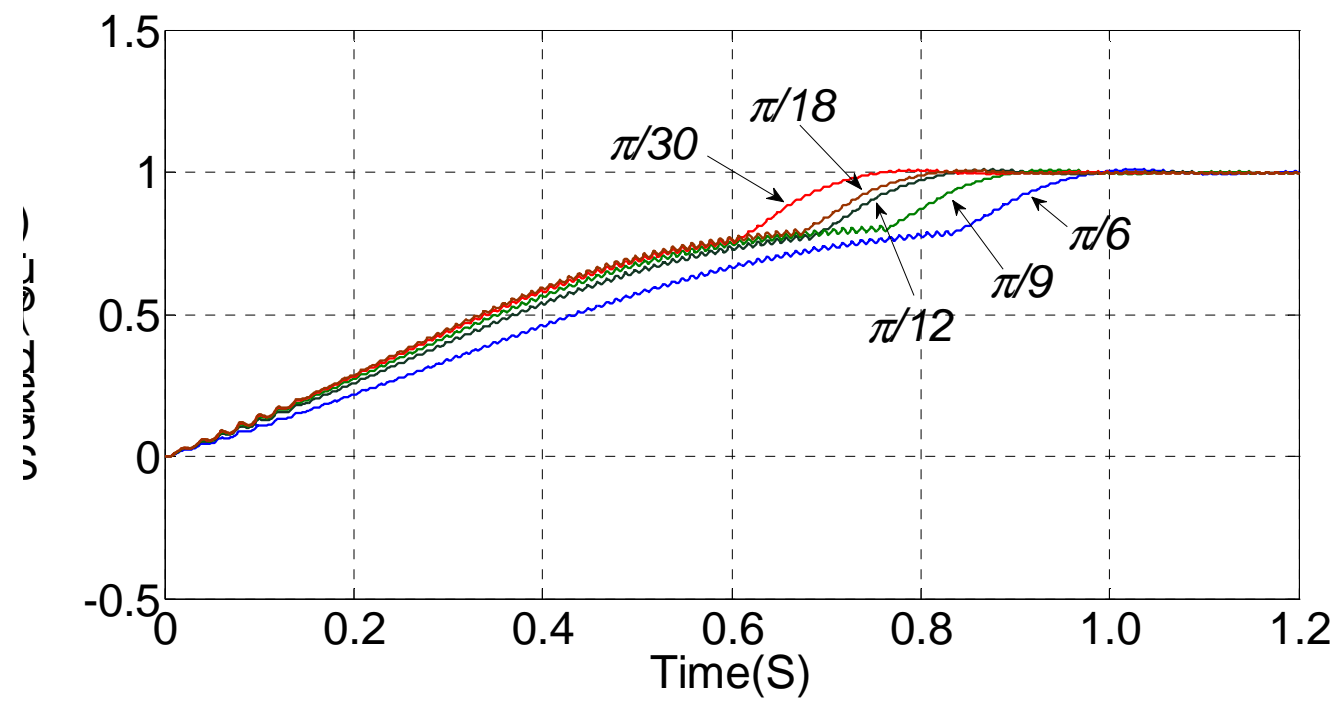

Figure 8. Speed vs time of split-phase motor for varying conduction angles for IGBT based starter.

Table 2. THD for various firing angle for IGBT based soft starter.

\begin{tabular}{|c|c|c|}
\hline Firing Angle $(\alpha)$ & \multicolumn{2}{|c|}{$\begin{array}{c}\text { Total Harmonic Distortion(THD) } \\
(\% \text { of Fundamental) }\end{array}$} \\
\hline & R-L load & Split-phase induction motor \\
\hline$\pi / 18$ & 4.09 & 22.16 \\
\hline$\pi / 12$ & 7.63 & 23.53 \\
\hline$\pi / 6$ & 23.13 & 37.65 \\
\hline$\pi / 4$ & 44.17 & 59.95 \\
\hline$\pi / 3$ & 74.86 & 95.14 \\
\hline
\end{tabular}

The THD at input side of voltage regulator is shown in Table 1 and Table 2 of thyristor and IGBT based soft starter, respectively. Comparing Table 1 and Table 2, it can be observed that for same value of firing angle ( $\alpha$ ), THD for an IGBT based Voltage Regulator is higher. This is due to fact that the voltage waveform is more distorted in the latter case.

The output voltage and current waveforms of IGBT based soft starter is shown in Fig. 9 at conduction angle of $\alpha$. 


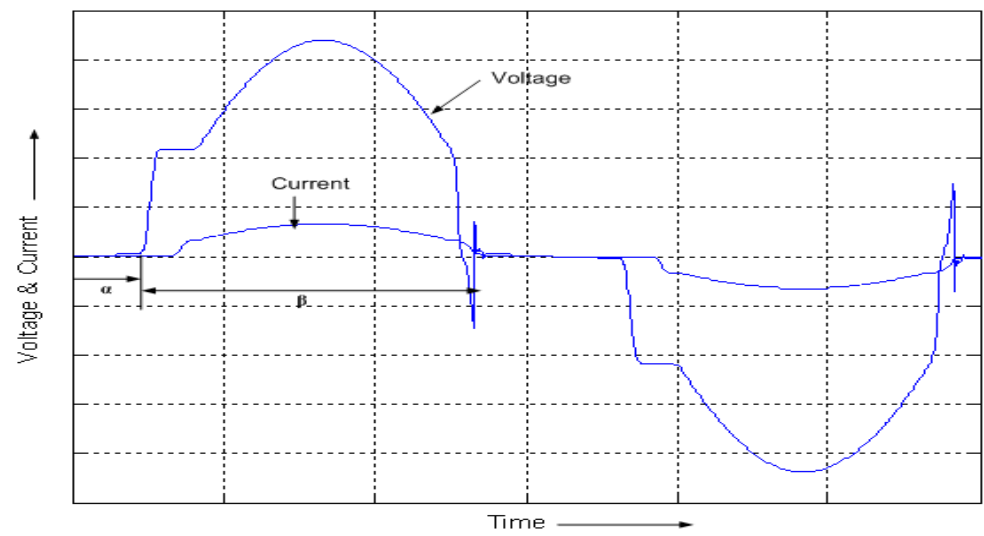

Figure 9. Output Voltage and Current for $\alpha=\pi / 6$.

The large spikes in the voltage waveform are basically due to presence of inductive load. From Fig. 9 it can be easily observed that the IGBTs are line-commutated device, i.e. it doesn't require any additional circuit for commutation purposes and the extinction angle(turn-off angle) is same as firing angle(turn-on angle) for each half cycle. Hence the conduction angle $\beta$ for this can be written as

$$
\beta=(\pi-2 \alpha)
$$

The rms output voltage is given by

$$
V_{o}=\left[\frac{1}{\pi} \int_{(\pi-\beta) / 2}^{(\pi+\beta) / 2} 2 V_{s}^{2} \sin ^{2}(\omega t) d(\omega t)\right]^{1 / 2}=V_{s}\left[\frac{1}{\pi}(\beta+\sin (\beta))\right]^{1 / 2}
$$

The input current of Fig. 9 can be expressed in Fourier series as

$$
i_{S}(t)=\sum_{n=1,3,5 \ldots}^{\infty} \sqrt{2} \sin \left(n \omega t+\phi_{n}\right)
$$

where

$$
\phi_{n}=\tan ^{-1} \frac{a_{n}}{b_{n}}=0
$$

The rms value of the $n$th harmonic input current is given as

$$
I_{s n}=\frac{1}{\sqrt{2}}\left(a_{n}^{2}+b_{n}^{2}\right)^{1 / 2}=\frac{2 \sqrt{2}}{n \pi} I_{a} \sin \left(\frac{n \beta}{2}\right)
$$

The rms value of the fundamental current is

$$
I_{s 1}=\frac{2 \sqrt{2}}{\pi} I_{a} \sin \left(\frac{\beta}{2}\right)
$$

The rms input current is found as

$$
I_{s}=I_{a} \sqrt{\frac{\beta}{\pi}}
$$

Harmonic factor

$$
H F=\left[\left(\frac{I_{s}}{I_{s 1}}\right)^{2}-1\right]^{1 / 2}=\left[\frac{\pi \beta}{4(1-\cos (\beta))}-1\right]^{1 / 2}
$$

Displacement factor 
Power factor

$$
D F=\cos \left(\phi_{1}\right)=1
$$

$$
P F=\left(\frac{I_{s 1}}{I_{s}}\right) D F=\frac{2 \sqrt{2}}{\sqrt{\beta \pi}} \sin \left(\frac{\beta}{2}\right)
$$

The advantage of using IGBTs is that due to same extinction angle as that of firing angle, the fundamental current in this case is in phase with the voltage, hence displacement factor becomes unity. A plot of the power factor vs firing angle is illustrated in Fig. 10. It reveals that the power factor varies significantly with change in the firing angle especially for IGBT based soft starter. Nevertheless, it is higher for thyristor based system.

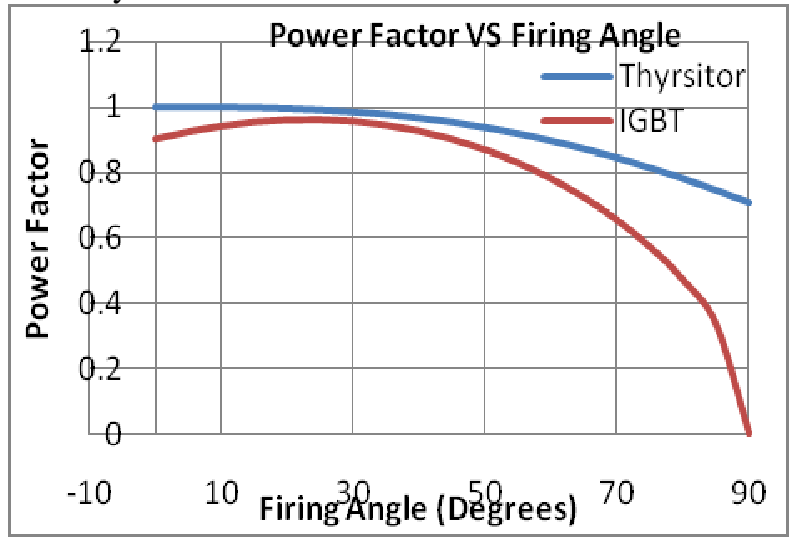

Figure 10. Power factor vs firing angle for Thyristor and IGBT based soft starters.

A point must be noted here that the power factor vs firing angle curve shown above is of the case when no filter is incorporated in the system, if the filters are also incorporated in the system, THD of the system reduces significantly and as already discussed above displacement factor is unity for this case, hence overall power factor improvement will be there. Further, since the harmonics in starters using IGBTs are of higher order, $\mathrm{L}$ and $\mathrm{C}$ requirement will be of lower value, hence of smaller size, on the other hand starters with thyristors have lower order harmonics requires filters with larger value of $\mathrm{L}$ and $\mathrm{C}$ which are of large size and non-economical in terms of both cost and area requirement. Thus while comparing the two types of starter based on filter requirements, it can be concluded that the IGBT based starter is a cheaper option due to smaller filter components requirement.

\subsection{Matlab $^{\circledR} /$ Simulink ${ }^{\circledR}$ Model of Three-phase soft Starter using Thyristor}

The basic three-phase induction motor drive scheme is illustrated in Figure 11, where the power switches can either be thyristors or IGBTs.

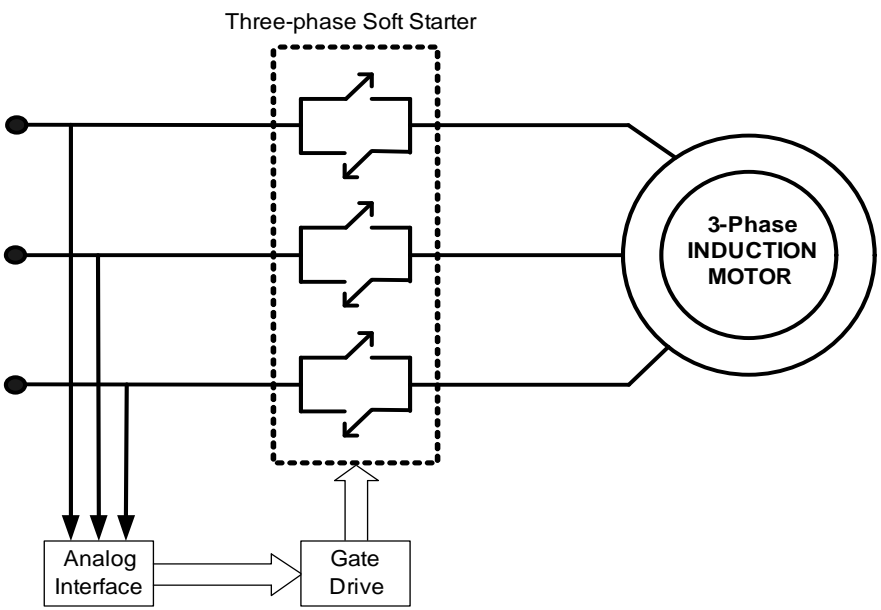

Figure 11. Schematic diagram of soft-starter controlled induction motor drive.

The simulation model of three-phase soft starter for three-phase induction motor is developed as shown in Figure 12 for thyristor based circuit. Three-phase sinusoidal voltages are generated using three independent voltage sources having phase difference of 
$120^{\circ}$ and magnitude of $220 \mathrm{Vrms}$. The output of soft starter is given to a three-phase induction motor. The outputs response of the motor is recorded and presented in Figure 13-15.

The output voltage waveform of thyristor based three-phase voltage regulator is shown in Figure 9 for $\alpha=\pi / 6$. The controllable range of voltage regulator is from firing angle, $\alpha=0$ to $\alpha=\pi / 2$. The Total Harmonic Distortion (THD) for higher values of $\alpha$ increases, which indicates increased harmonic content in the line current and voltage.

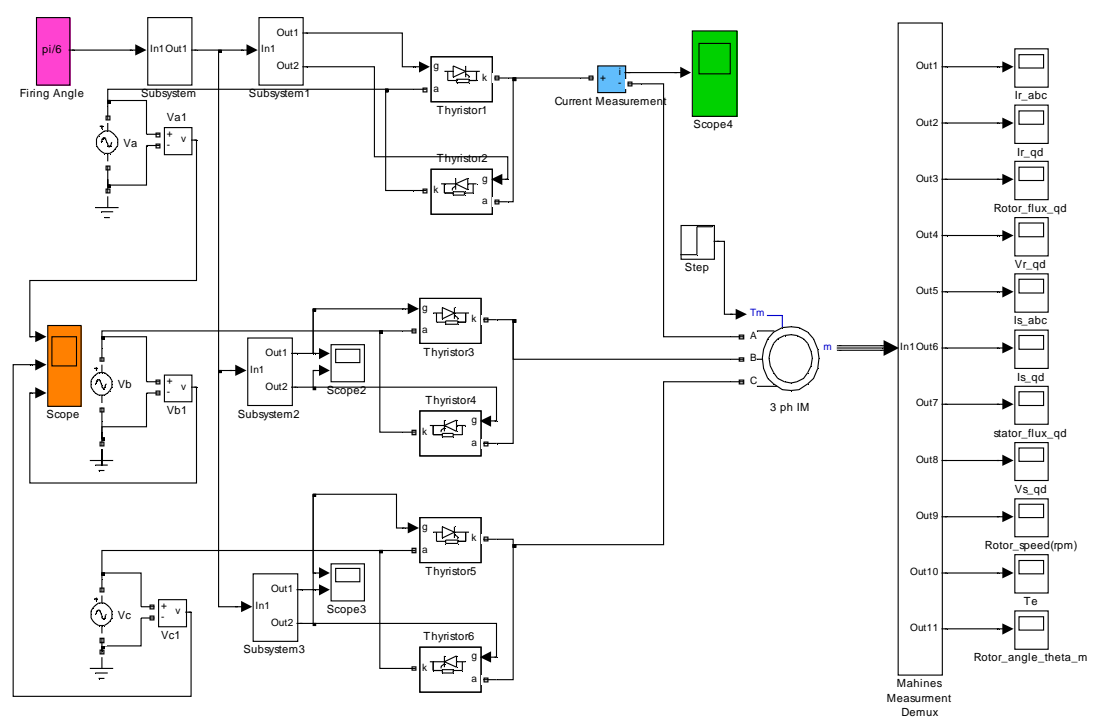

Figure 12. Simulink Model of Induction Motor fed from thyristor based soft starter

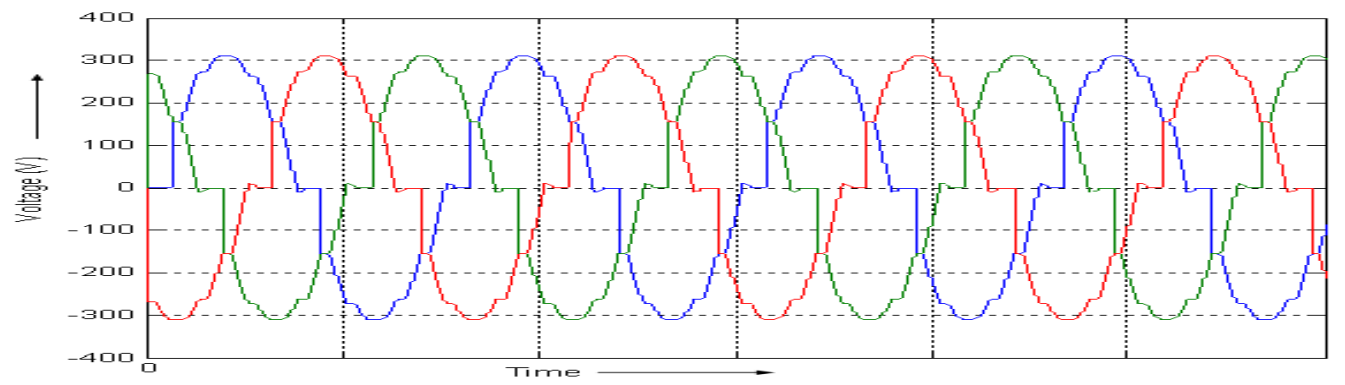

a.

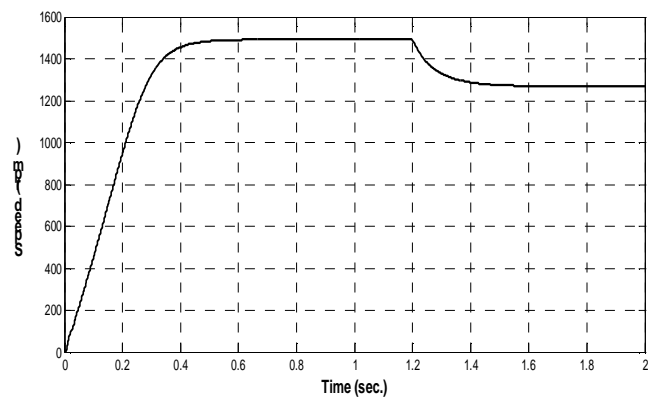

b.

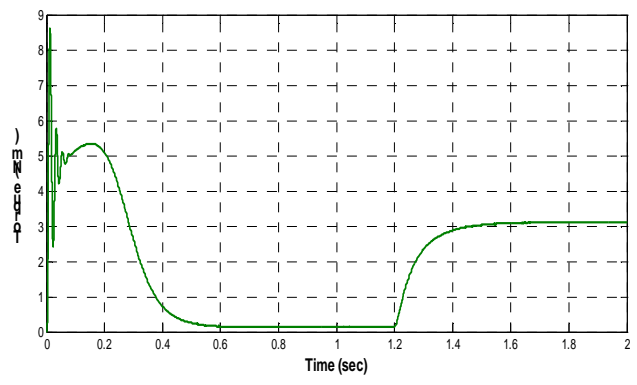

c.

Figure 13. Induction motor response for $\alpha=\pi / 6$; a. output voltage, b. Speed Vs Time curve and c. Torque Vs Time curve for noload. 


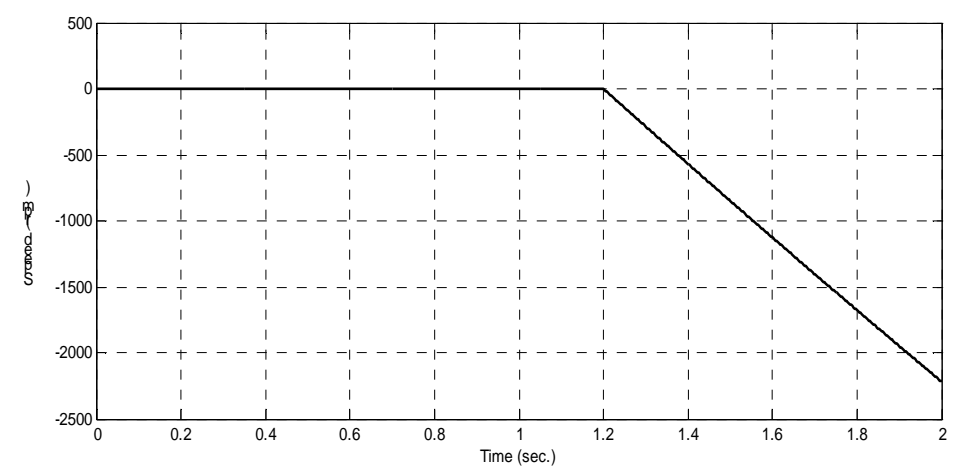

Figure 14. Speed vs. time curve for $\alpha=\pi / 3$ when load is applied at $t=1.2 \mathrm{sec}$.

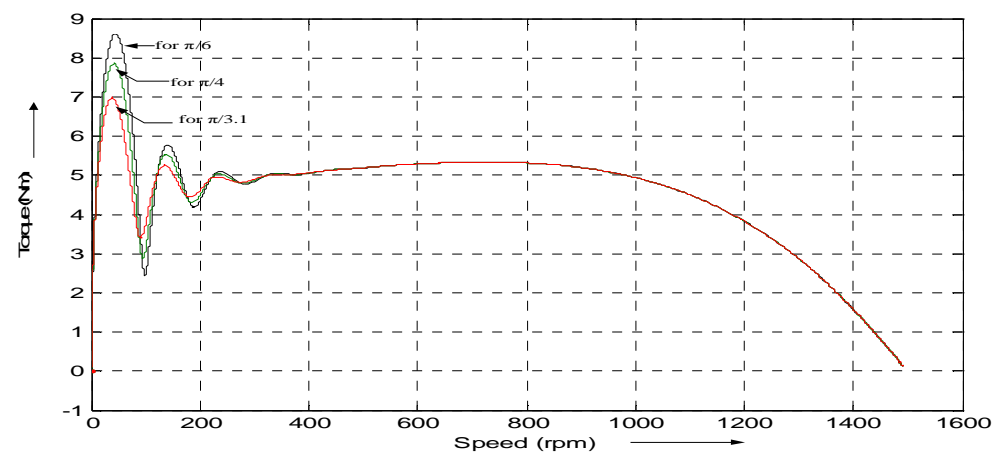

Figure 15. Torque vs. speed curve for different value of firing angle at no-load.

The drive system shows a typical behaviour for different values of firing angle i.e., $\alpha=\pi / 6, \pi / 4, \pi /(3.1)$. The motor is taking up the load well with a reduction in the corresponding speed. There is a reduction in the peak torque for change in the firing angle as expected. From Figure 13 it is observed that motor performs satisfactorily at $\alpha=\pi / 6$, but when the magnitude of $\alpha$ is increased beyond the value $\pi / 3.1$, the motor become unstable (as shown in Figure 14). Hence, the value of $\alpha$ should be $\leq \pi /$ (3), for a thyristor based soft starter for stable operation of the drive system.

In Figure 15, the speed-torque characteristics of motor are shown under various loading conditions and the variations of torque speed curves with respect to the applied voltage are shown. It can be noted that increasing the firing angle results in decrease in starting torque. These curves show that the slip (hence speed) at maximum torque s' remains same (in both transient as well as steady state condition). The speed range for stable operation remains the same. The slope and shape of the characteristics are dependent ultimately on the machine parameters. The curve shows both the transient as well as steady state characteristic. It is to be noted here is that, if the applied voltage is reduced, the voltage across the magnetizing branch also comes down. This in turn means that the magnetizing current and hence flux level are reduced. Reduction in the flux level in the machine impairs torque production. If, however, the machine is running under lightly loaded conditions, then operating under rated flux levels is not required. Under such conditions, reduction in magnetizing current improves the power factor of operation. Some amount of energy saving may also be achieved.

It is also noted that the starting torque is also lower at lower voltages. Thus, even if a given voltage level is sufficient for achieving the running torque, the machine may not start. This method of speed control is best suited for loads that require very little starting torque. It is further noted that the torque response are identical under steady state conditions. Thus only the transients are affected by the choice of the firing angle.

\subsection{Matlab $^{\circledR} /$ Simulink $^{\circledR}$ model of three-phase soft starter using IGBT}

Simulation model is developed for soft starting method using IGBT as power switches as shown in Figure 16. The only difference is the power switch, the rest of the parameters are kept same as the one of section 2.3. The motor is allowed to run with a firing angle of $\pi / 6$ to $\pi / 3$ and the resulting waveforms are illustrated in Figure 17 (for $\alpha=\pi / 6$ ). The results of firing angle equal to $\pi / 3$ is not repeated here as they give similar results as the one obtainable with the thyristor based system. Large spikes are seen in the output voltages. This is due to sudden interruption of the inductive current contrary to thyristor case where the current was slowly reduced to zero. The speed ripple is clearly visible in the speed response (Figure 17b) of the motor. This pulsation is of the order of $\pm 5 \mathrm{rpm}$. 


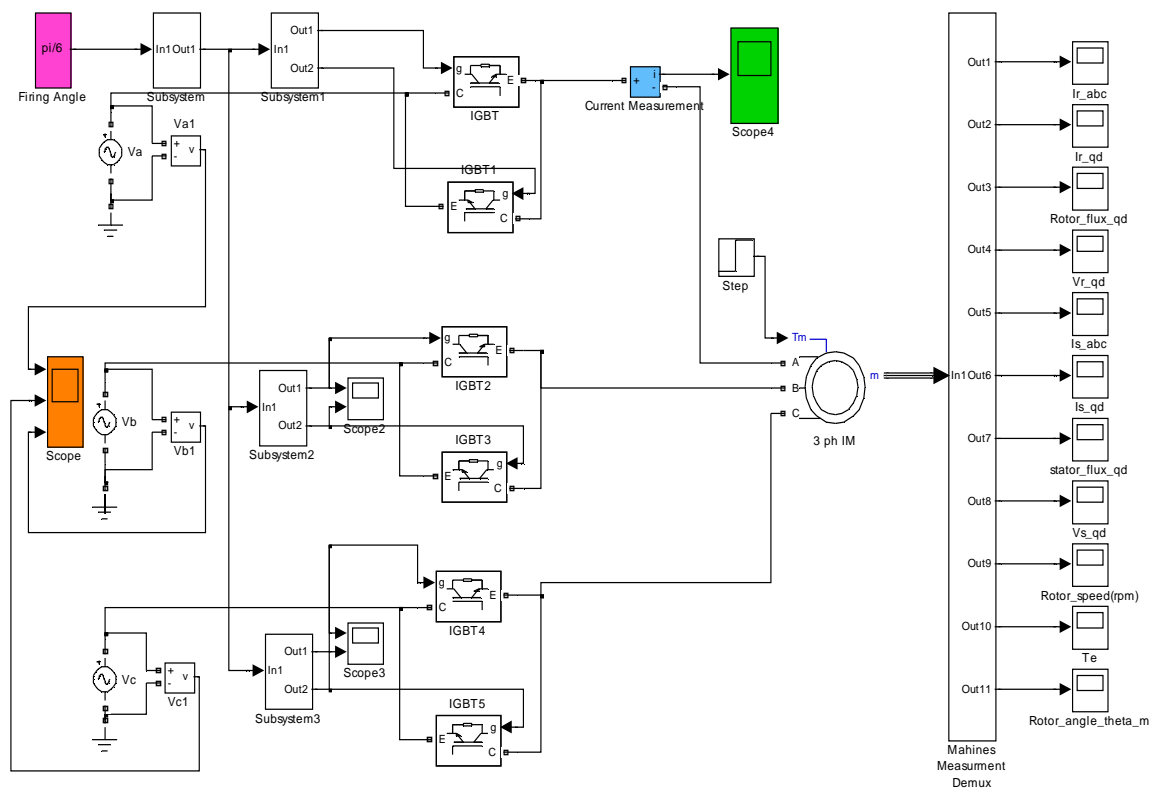

Figure 16. Simulink Model of Induction Motor fed from IGBT based soft starter.

The torque-speed characteristic shows large fluctuation, this is basically due to large amount of distortion in the output voltage of the starter. Hence it also needs consideration that the applied voltage should not be much distorted, and harmonic filters must be incorporated for stable operation of the drive system. It is observed that motor cannot perform satisfactorily even at very low value of firing angle due to large amount of harmonics in the supply to the motor.

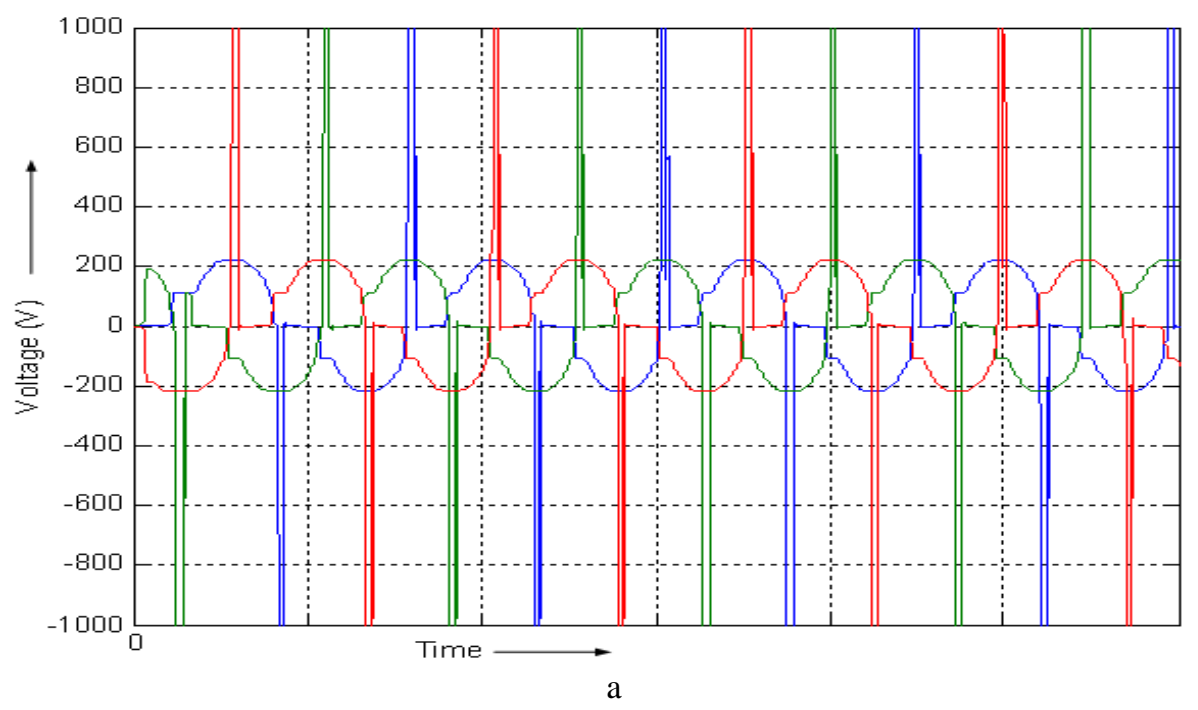

Figure 17. Induction motor response to IGBT based soft starter for $\alpha=\pi / 6$ : a. output voltage 


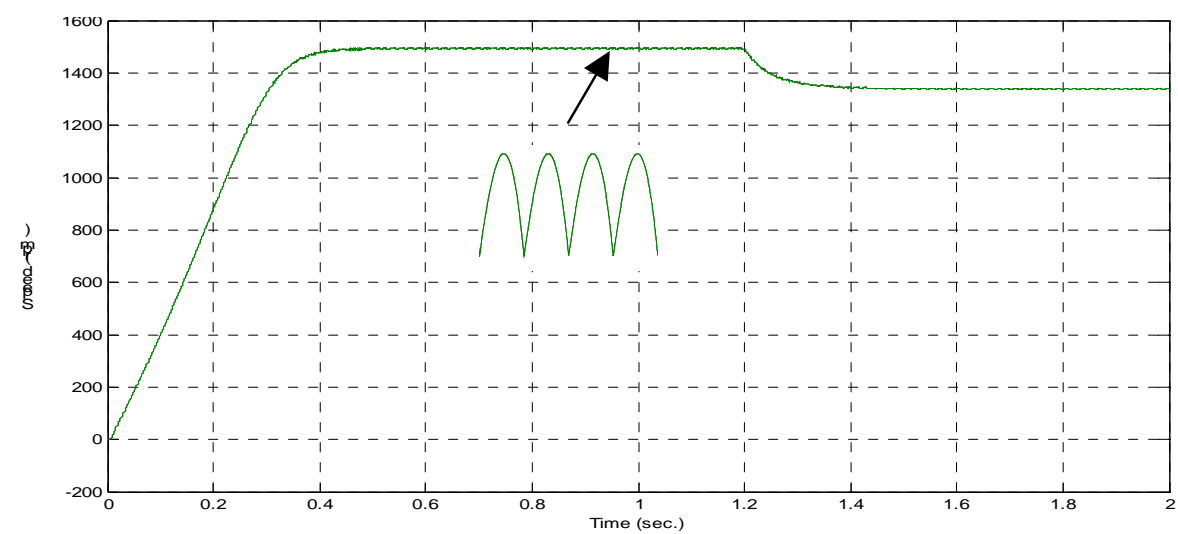

b

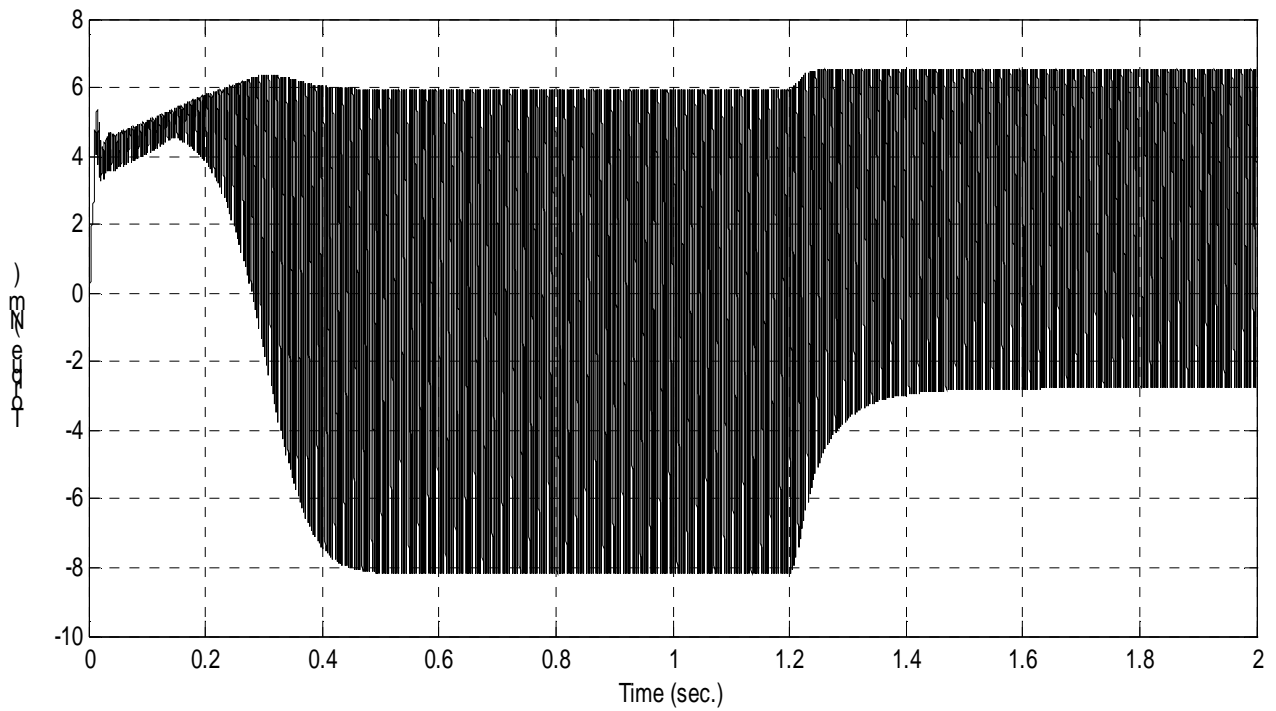

c.

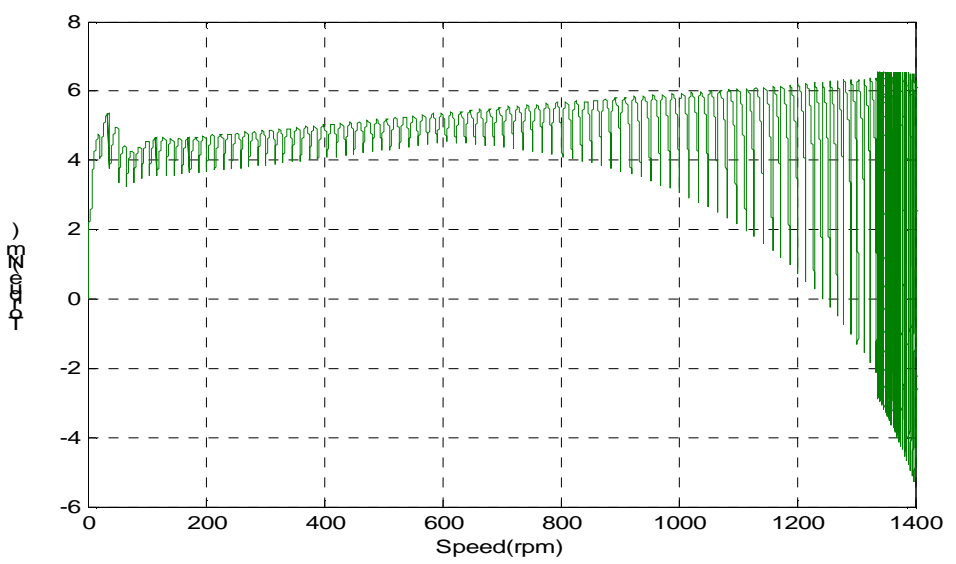

d.

Figure 17 (cont'd). Induction motor response to IGBT based soft starter for $\alpha=\pi / 6$ : b. speed, c. torque vs time and d. torque vs speed. 


\section{Experimental results}

\subsection{Single phase starter}

The implementation of ac-ac converters is more complex than other type of converters, this is because of the operational complexity of the semiconductor switches. The major challenge in the design of ac-ac converter is their commutation requirements. Single and three-phase soft starters are developed in the laboratory. The analogue implementation circuit for singlephase soft starter is shown in Fig. 18 and its pictorial representation is provided in Figure 19. IGBT based soft starter is developed due to its higher switching frequency characteristic. The experimental waveforms are shown in Figure 20.

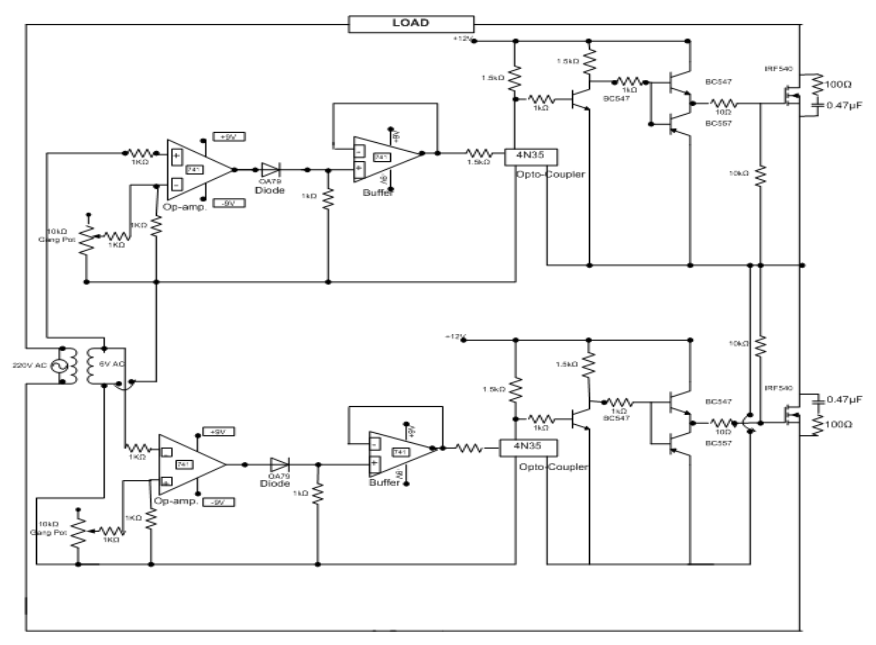

Figure 18. Circuit Diagram for single-phase soft starter using IGBT.

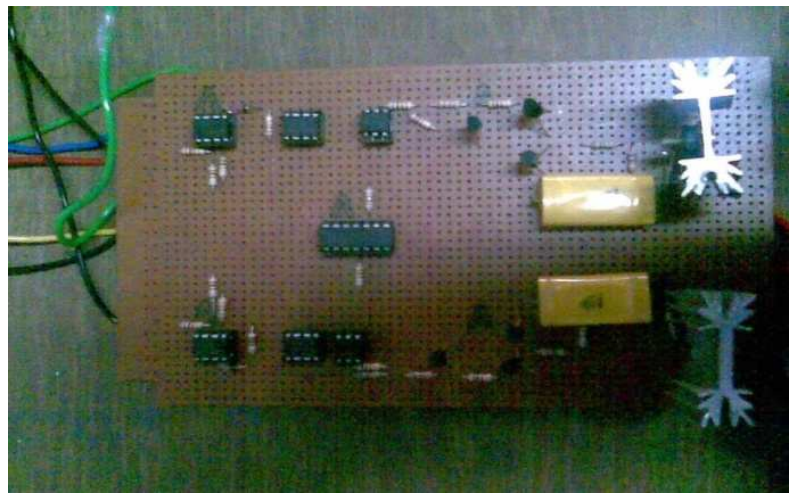

Figure 19. Fabricated single-phase soft starter
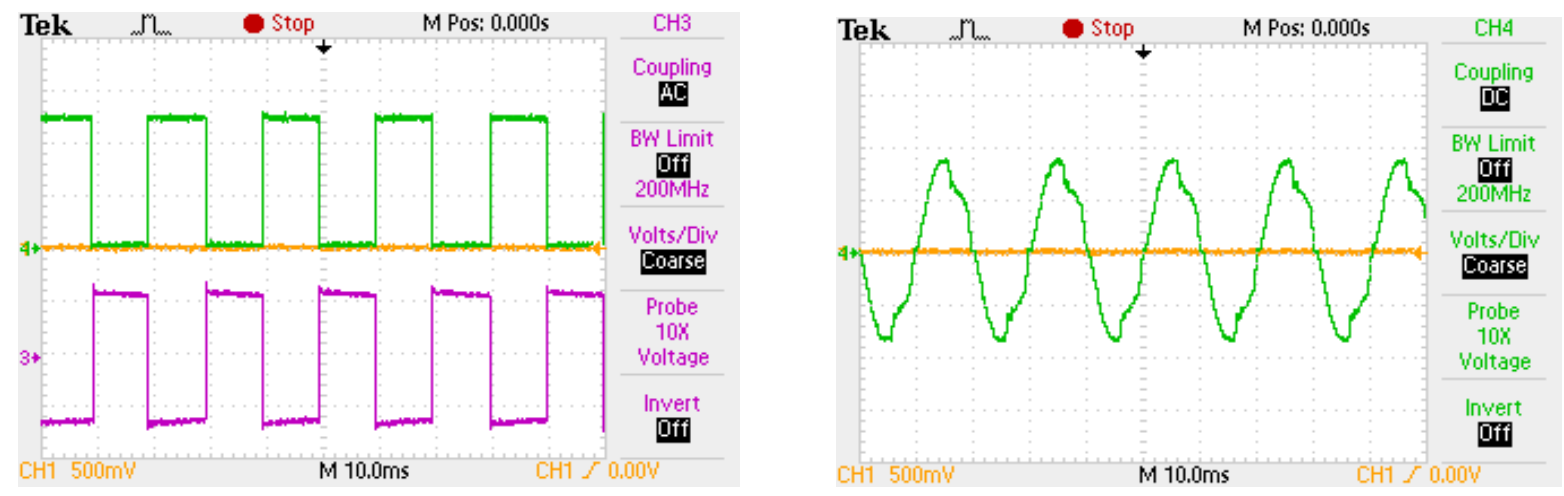

Figure 20a. Gate pulses and output voltage for firing angle, $\alpha=0^{0}$. 

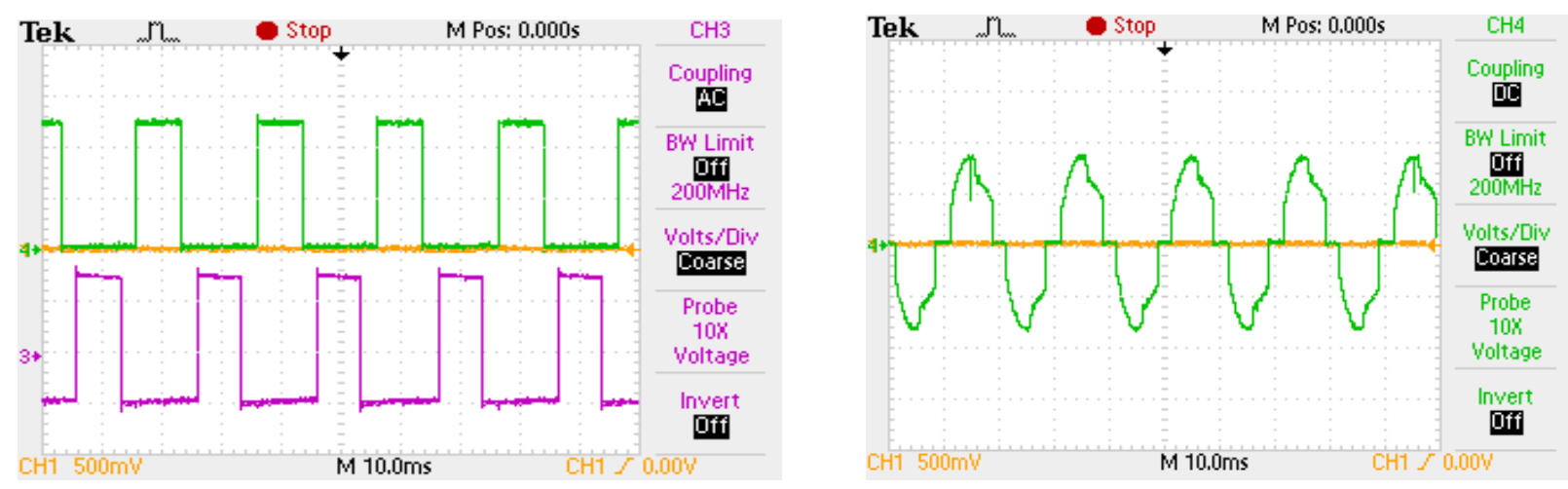

Figure 20b. Gate pulses and output voltage for firing angle, $\alpha=\pi / 6$.

\subsection{Three-phase soft starter}

The pictorial representation of the developed three-phase soft starter is shown in Figure 21. Basically it is made by parallel connection of three single-phase soft starters. The experimental waveforms are shown in Figure 22.

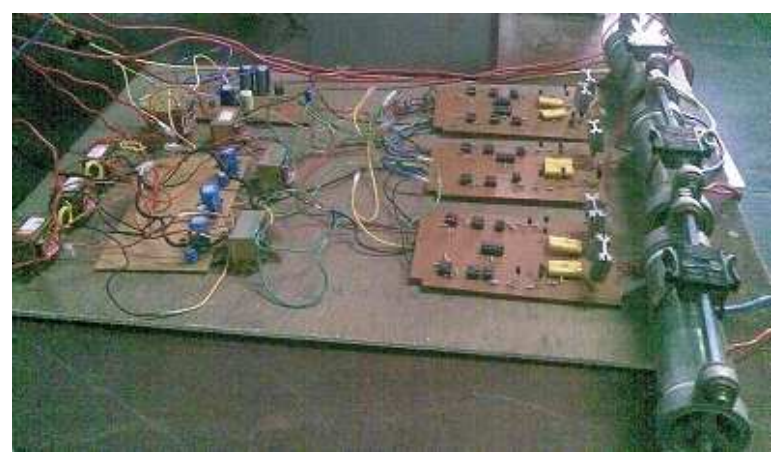

Figure 21. Fabricated three-phase ac voltage regulator using IGBT.
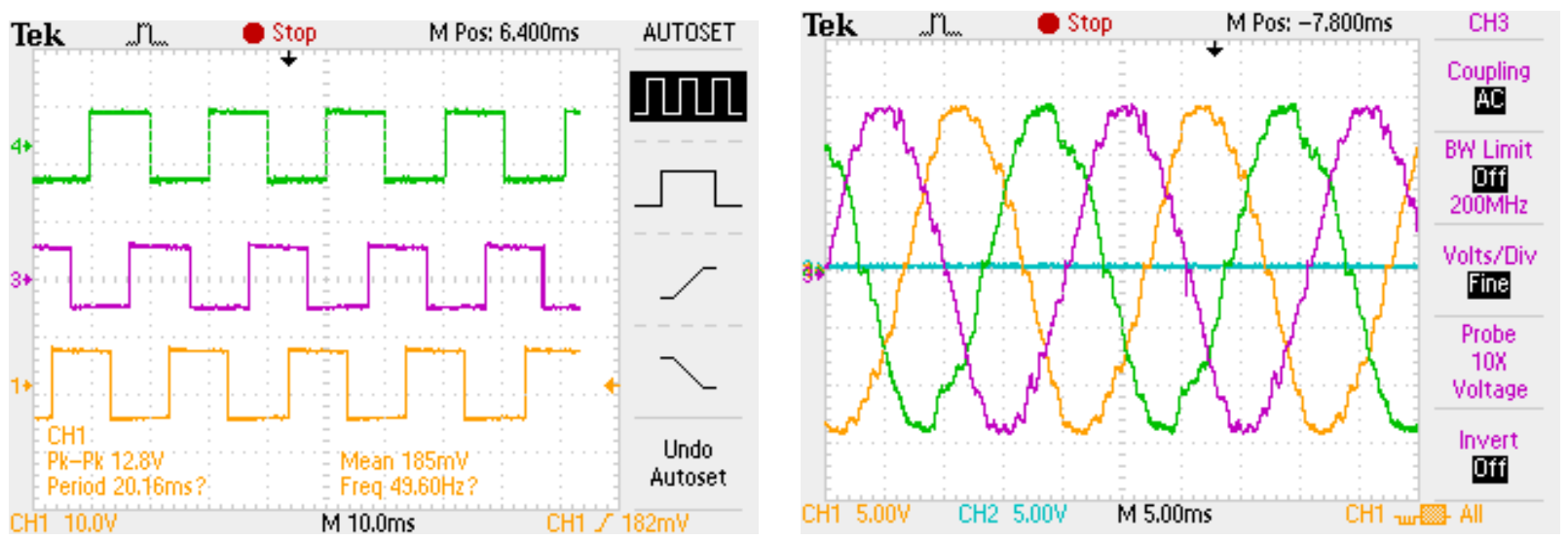

Figure 22a. Gate pulses and output voltage of all three phase for firing angle, $\alpha=0^{0}$.

The controllable range is kept from $\alpha=0$ to $\alpha=\pi / 6$, although this range can be increased by slight modification in the circuit but a higher value of firing angle means much lower applied voltage that may lead to destabilization of drive system. 

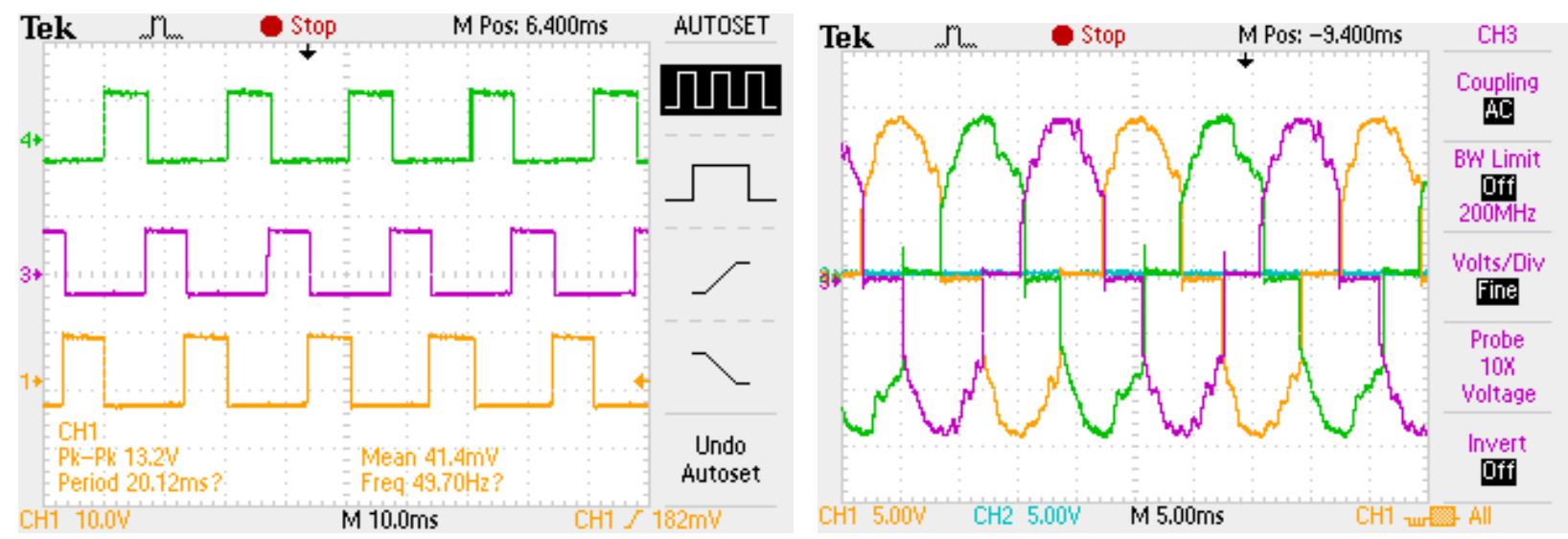

Figure 22b. Gate pulses and output voltage of all three phase for firing angle, $\alpha=\pi / 6$.

\section{Conclusion}

In this paper simulation model of single-phase and three-phase soft starters for induction motors (thyristor and IGBT based) is developed and the results are evaluated. The paper discusses the performance of single-phase and three-phase induction motor drive supplied from a variable voltage soft starter. It is concluded that the firing angle of thyristors should be $\leq \pi / 3$ for stable operation of the drive system. For larger values of the firing angle, fluctuation in speed is observed and in worst cases motor may fail to start. Further, it is concluded that IGBTs should not be used as power switch without harmonic filters, since use of IGBT only results in large amount of distortion in the input voltage to the induction motors which may results in instability of the drive system. The preliminary experimental results are presented. The output voltage shows that the designed system is working satisfactorily. The test on motor will be reported further.

\section{Nomenclature}

$\alpha \quad$ Conduction angle

$\beta \quad$ Extinction angle

$V_{o} \quad$ Output RMS voltage

$I_{o} \quad$ Output RMS Current

$I_{s n} \quad n^{\text {th }}$ harmonic input current

$I_{s} \quad$ Input RMS current

$H F \quad$ Harmonic Factor

$D F \quad$ Displacement Factor

$P F \quad$ Power Factor

\section{References}

Bruce F.M., Graefe R.J., Lutz A. amd Panlener M.D., 1984. Reduced voltage starting of squirrel cage induction motors, IEEE Trans. Ind. Appl. Vol. IA-20, pp. 46-55.

Charles S. and Bhuvameswari G., 2009. Power quality studies on a soft start for an induction motor, Int. Journal of Recent Trends in Engg., Vol. 1, No. 3, pp. 261-265.

Deleroi W., Woudstra J.B. and Fahim A.A., 1989. Analysis and application of three-phase induction motor voltage controller with improved transient performance, IEEE Trans. On Ind. Appl. Vol. 25, pp. 280-286.

Eltamaly A.M., Alolah A.I., Hamouda R., and Abdulghany M.Y., 2009. A novel digital implementation of ac voltage controller for speed control of induction motor, Journal of World Academy of Science, Engineering and Technology, Vol. 54, pp. 48-53.

Eltamaly A.M., Alolah A.I. and Hamouda R.M., 2007a. Performance evaluation of three-phase Induction motor under different AC voltage control strategies: Part 1, Proc. Int. Applied Electric Machine and Power Electronics ACEMP '07, pp. 770-774, 1012 Sept. 2007.

Eltamaly A.M., Alolah A.I. and Hamouda R.M., 2007b. Performance Evaluation of three-phase Induction motor under different AC voltage control strategies 'Part II, Proc. Int. Applied Electric Machine and Power Electronics ACEMP '07, pp. 17-22, 10-12 Sept. 2007.

Gastli A. and Ahmed M.M., 2005. ANN based soft starting of voltage controlled fed Induction machine drive system, IEEE Trans. on Energy Conv., Vol. 20, No. 3, pp. 497-503.

Hamed S., and Chalmers B., 1990. Analysis of variable-voltage thyristor controlled induction motors, IEE Proc., Vol. 137, No. 3, Pt. B, pp. 184-193. 
Jang D-H. and Choe G-H., 1998. Step-up/Down Ac voltage regulator using transformer with tap changes and PWM ac chopper, IEEE Trans. on Ind. Elect., Vol. 45, No. 6, pp. 905-911.

Kashif A.R. and Saqib M.A., 2007. Soft starting of an induction motor using adaptive neuro fuzzy interface system", Proc. Int. Conf. on Electrical Engg., ICEE 07, pp. 1-5,11-12 April 2007.

Lipo T.A., 1971a. Multiple reference frames applied to impedance unbalances of induction machinery-the open circuited stator phase, IEEE Conf. on Systems, Networks and Computers, Mexico, pp. 312-316.

Lipo T.A., 1971b. The analysis of induction motors with voltage control by symmetrically triggered thyristors, IEEE Trans. on Power Apparatus and Systems, Vol. PAS-90, No. 2, pp. 515-525.

Mazda F.F., 1973. Thyristor Control of AC Motors", Newnes- Butterworth.

Mozdzer A. and Bose B.K., 1976. Three-phase ac power control using power transistors, IEEE Trans. Ind. Appl., Vol. 1A- 12, pp. 499- 505.

Nevelsteen J. and Aragon H., 1989. Starting of large motors-methods and economics, IEEE Trans. Ind. Appl., Vol. IA-25, pp. 1012-1018.

Rashid M.H., 1993. Power Electronics Circuits Devices and Applications, Second Edition, Prentice-Hall Inc, Englewood Cliff, New Jersey.

Rowan T.M., Merrison J.C., 1991. Electric motor speed control apparatus and Method, U.S. Patent 4996470, Feb. 1991.

Shephard W., 1976. Thyristor Control of AC Circuits, Bradford. England: Bradford University Press.

Vazquez N., Velazquez A., Hernandez C., Rodriguez E. and Oroso R., 2008. A fast ac voltage regulator, Proc. $11^{\text {th }}$ IEEE Int.

Power Electronic Congress, pp. 162-166, 24-27 Aug. 2008.

Williams A.J. and Griffth M.S., 1978. Evaluating the effects of motor starting on industrial and commercial power systems, IEEE

Trans. Ind. Appl. Vol. IA-14, pp. 292-299, July/Aug. 1978.

Zenginobuz G., Cadirci I., Ermis M. and Barlak C., 2004. Performance Optimisation of Induction motors during voltage controlled soft starting, IEEE Trans. on Energy Conversion, Vol. 19, No. 2, pp. 278-288, June 2004.

Zhong T., Zhu L., Zhou M. and Dai Y., 2009. Study on the simulation of the soft start of the asynchronous motor with pump control function based on thyristor, Journal of Modern Applied Science, Canada, Vol.3, No. 5, pp. 112-119.

\section{Biographical notes}

Ahmed Riyaz born at Muzzaffarpur, Bihar, India and did his schooling from New Delhi, India. Has did his M.Tech. (Power System \& Drives) and B.Tech. (Electrical) Engineering from the Deptt. Of Electrical Engg., Aligarh Muslim University, Aligarh, India in 2009 and 2007 , respectively. His area of research includes Electric Drives and Power Electronics.

Atif Iqbal received his B.Sc. and M.Sc. Engineering (Electrical) degrees in 1991 and 1996, respectively, from the Aligarh Muslim University, Aligarh, India and PhD in 2006 from Liverpool John Moores University, UK. He has been employed as Lecturer in the Department of Electrical Engineering, Aligarh Muslim University, Aligarh since 1991 and is working as Associate Professor in the same university. He is presently with Texas A\&M University at Qatar on research assignment. He is recipient of Maulana Tufail Ahmad Gold Medal for standing first at B.Sc. Engg. Exams in 1991 at AMU, and EPSRC, Govt. Of UK, fellowship from 2002-2005 for pursuing PhD studies. His principal research interest is Modelling and Control of Power Electronics Converters \& Drives.

Shaikh Moinuddin received his B.E. and M.Tech (Electrical) degrees in 1996 and 1999, respectively, from the Aligarh Muslim University, Aligarh, India. He has completed his PhD in 2009 on multi-phase inverter modeling and control from AMU. He is recipient of University Gold Medals for standing first in Electrical branch and in all branches of Engineering in 1996 B.E. exams. He has served Indian Air Force from 1971 to 1987. He is employed in the University Polytechnic, Aligarh Muslim University since 1987 where he is currently working as a Lecturer. His principal areas of research interest is Power Electronics and Electric Drives.

Sk Moin Ahmed born in 1983 at Hoogly, West Bengal, India. He received his B.Tech (Electrical) and M.Tech. (Power System \& drives) in 2006 \& 2008, respectively, from Department of Electrical Engineering, Aligarh Muslim University, Aligarh. He is gold medalist for securing top position in M.Tech. He is a recipient of Torento fellowship funded by AMU. Currently he is pursuing his PhD at AMU and employed as Senior research fellow in a CSIR, New Delhi, funded project.

Haitham Abu-Rub has done his PhD from Gdansk University, Poland in 1995 and MSc in Electrical Engg From Gdynia Maritime University. He is presently serving as Visiting Senior Associate Professor in the Deptt. Of Electrical \& Computer Engg., Texas A\&M University at Qatar. His areas of interest are Field oriented control of electrical machines, nonlinear control of electrical drive, sensorless control, parameters estimation, power electronics, and electrical machines. Has earned many international prestigious awards like the American Fulbright Scholarship (Texas A\&M University), the German Alexander von Humboldt Fellowship (Wuppertal university), the German DAAD Scholarship (Bochum University), and the British Royal Society Scholarship (Southampton University). Also received the "Best Presentation Award" at the 27th Annual Conference of the IEEE Industrial Electronics Society in Denver (IECON'01).

Received July 2009

Accepted September 2009

Final acceptance in revised form September 2009 